\title{
Successful use of combined blood purification techniques in splenectomised patient with septic shock in streptococcus pneumoniae infection - a case report
}

\author{
Andreja Sinkovic ${ }^{*}$, Barbara Kit and Andrej Markota
}

\begin{abstract}
Background: Septic cardiomyopathy represents cardiac impairment in sepsis and is a part of systemic involvement in sepsis. Cytokine storm is responsible for septic shock and for myocardial dysfunction of potentially reversible septic cardiomyopathy. Several case reports and case series demonstrated successful removal of circulating cytokines by combined blood purification techniques. In this way, septic shock and survival of septic patients improved. However, the evidences for reversal of myocardial dysfunction are rare.

Case presentation: We present a patient with a history of chemotherapy for coat cell lymphoma, splenectomy and autologous bone marrow transplantation, who suffered severe pneumococcal sepsis, septic shock and septic cardiomyopathy, resistant to pharmacological therapy. Combined blood purification techniques $36 \mathrm{~h}$ after the start of treatment successfully decreased Interleukin-6 level, lactacidosis, the need for vasopressors to maintain normotension, improved systolic function of the left ventricle and clinical outcome.

Conclusions: Our case suggests that combined blood purification techniques initiated even $36 \mathrm{~h}$ after the start of treatment successfully removed inflammatory cytokines, reversed circulatory failure and improved left ventricular systolic function in pneumococcal sepsis.
\end{abstract}

Keywords: Sepsis, Septic cardiomyopathy, Septic shock, Combined blood purification techniques

\section{Background}

Septic cardiomyopathy presents cardiac dysfunction as a part of systemic involvement in sepsis [1-3]. It is acute and completely reversible, if the patients survive. It still is a condition of high prognostic importance because it accounts for approximately $10 \%$ of the fatalities observed in sepsis and septic shock [1-3]. Some data suggest, that nonsurvivors have more depressed afterload-related myocardial dysfunction than survivors have [1].

Septic cardiomyopathy occurs in up to $65 \%$ of septic patients, according to echocardiographic measurements of ejection fraction (EF). Depressed LV systolic function in septic cardiomyopathy is associated with normal or low left ventricular filling pressure, unlike the pattern of

\footnotetext{
* Correspondence: andreja.sinkovic@guest.arnes.si

Department of medical intensive care medicine, University clinical centre Maribor, Ljubljanska 5, 2000 Maribor, Slovenia
}

cardiogenic shock, where the left ventricular pressures are elevated [2].

In sepsis with significant afterload reduction (because of decreased systemic vascular resistance), left and right ventricular cardiac output and stroke volumes are not adequately increased or are even depressed. In septic cardiomyopathy, we can find global and/or regional contractile disturbances as well as diastolic dysfunction. Increased left ventricular compliance with a shift of the pressure-volume curve to the left causes considerable dilation of the left and right heart, which is a prognostically positive sign, according to some studies $[1,2]$.

Acute systolic myocardial dysfunction of the left ventricle in cases with septic cardiomyopathy contributes significantly to hypotension in septic shock [1-3].

Circulating factors responsible for systolic myocardial dysfunction in sepsis are toxins, cytokines, cardio depressant

(c) The Author(s). 2018 Open Access This article is distributed under the terms of the Creative Commons Attribution 4.0 International License (http://creativecommons.org/licenses/by/4.0/), which permits unrestricted use, distribution, and reproduction in any medium, provided you give appropriate credit to the original author(s) and the source, provide a link to the Creative Commons license, and indicate if changes were made. The Creative Commons Public Domain Dedication waiver (http://creativecommons.org/publicdomain/zero/1.0/) applies to the data made available in this article, unless otherwise stated. 
factors, etc. Complement activation and apoptosis are important as well. Among cardio depressant cytokines TNF- $\alpha$ increases intracellular nitric oxide, mitochondrial dysfunction of the cardiomyocytes and even phosphorylation of troponin I and thus reducing cardiac myofilament response to $\mathrm{Ca}^{2+}[1,2]$. Proinflammatory cytokines depress myocardial function, but also stimulate cytokine production in the heart, in particular IL-6 [1, 2, 4, 5]. Cytokine storm in sepsis, in particular the release of IL-6, results in hemodynamic instability in septic shock [6].

In animal and human studies, removal of circulating cytokines by blood purification techniques improves hemodynamic status and survival in sepsis [7-9].

Several case reports and case series demonstrated successful removal of circulating cytokines by hemoadsorption membranes such as CytoSorb ${ }^{\circ}[9,10]$. However, the evidence for reversal of systolic myocardial dysfunction by blood purification technique combined with hemoadsoption, are rare. Our purpose was to demonstrate the efficacy of cytokine removal by combined use of continuous veno-venous hemofiltration $(\mathrm{CVVH})$ and hemoadsorption by CytoSorb ${ }^{\circledR}$ in treatment of a patient with septic shock and septic cardiomyopathy, resistant to vasopressors and inotropes.

\section{Case presentation}

52-year old woman with a history of chemotherapy for coat cell lymphoma in 2011, splenectomy in 2013 and autologous bone marrow transplantation in 2014 was admitted to the medical intensive care unit (ICU) after having fever up to $38.7{ }^{\circ} \mathrm{C}$ and malaise for $24 \mathrm{~h}$. On admission, she was somnolent; the skin was cold, wet and pale; body temperature was $38{ }^{\circ} \mathrm{C}$, blood pressure $50 / 40 \mathrm{mmHg}$ and puls $120 / \mathrm{min}$. She was eupnoeic with oxygen saturation (SatO2) of $100 \%$ by pulse oximetry, inspiring $2 \mathrm{~L}$ of oxygen by nasal cannula. Clinical examination revealed rales over both lungs and tachycardia without heart murmurs. Abdomen was soft and painless with audible peristalsis. Standard electrocardiogram (ECG) showed sinus tachycardia of $125 / \mathrm{min}$.

On admission, we started continuous ECG monitoring, pulse oximetry, non-invasive blood pressure measurements and inserted central venous, arterial and urine catheters to measure central venous pressure intermittently, arterial blood pressure continuously and diuresis per hour.

We suspected sepsis with septic shock and immediately started treatment of shock and diagnostic procedures for sepsis. We managed shock initially by rapid infusion of crystalloids until we confirmed fluid unresponsiveness by ultrasound of inferior vena cava, demonstrating its diameter of $2.2 \mathrm{~cm}$, that did not change with inspiration. Therefore, we started noradrenalin infusion within the first $15 \mathrm{~min}$ and up titrated it to $66 \mu \mathrm{g} / \mathrm{min}$. In addition, bedside echocardiography showed decreased ejection fraction $(\mathrm{EF})$ of the left ventricle to $20 \%$. We added dobutamine infusion, but also glucocorticoids and later on vasopressin to reach normotension.

From the very start we suspected pneumonia on clinical grounds and confirmed it by bilateral infiltrates on chest rentgenograph. Among admission laboratory data we observed lactacidosis (arterial pH 7.24, bicarb $13.4 \mathrm{mmol} / \mathrm{l}$, $\mathrm{pCO}_{2} 4.24 \mathrm{kPa}, \mathrm{pO}_{2} 13 \mathrm{kPa}$, lactate $7.5 \mathrm{mmol} / \mathrm{l}$ ), thrombocytopenia $\left(62 \times 10^{3} / \mu \mathrm{L}\right)$, leucocytosis, increase of procalcitonin to $100 \mathrm{ng} / \mathrm{ml}$, C-reactive protein (CRP) to $166 \mathrm{mg} / \mathrm{l}, \mathrm{N}$-terminal-pro brain natriuretic peptide (NT-proBNP) to $2114 \mathrm{pmol} / \mathrm{l}$, myoglobin to $482 \mu \mathrm{g} / \mathrm{l}$, and serum creatinine to $288 \mu \mathrm{g} / \mathrm{l}$. Admission SOFA score was eight. We collected hemocultures, urinoculture and aspirates as soon as possible and after that immediately administered imipenem $500 \mathrm{mg} / 6 \mathrm{~h}$ IV.

After the first $24 \mathrm{~h}$ positive pneumococcal urine antigen confirmed streptococcal pneumonia. We continued imipenem therapy and adjusted the dose to renal failure. Other microbiological cultures remained negative. Together with the specialist for infectious disease we decided to continue imipenem therapy due to prior disease, including splenectomy.

After $24 \mathrm{~h}$ of ICU-stay the patient needed $40 \%$ oxygen by mask to achieve satisfactory blood gases $(\mathrm{pH} 7.2$, bicarb $15 \mathrm{mmol} / \mathrm{l}, \mathrm{paCO}_{2} 5.35 \mathrm{kPa}, \mathrm{paO}_{2} 8.5 \mathrm{kPa}$ ), her body temperature was $38{ }^{\circ} \mathrm{C}$. SatcrO ${ }_{2}$ was $76.1 \%$. Luckily, the patient did not need neither non-invasive, nor invasive ventilation during the entire ICU stay.

In spite of all treatments, after the first $24 \mathrm{~h}$ multiorgan failure syndrome persisted, including severe systolic myocardial dysfunction with left ventricular EF of $20 \%$, measured by echocardiography. SOFA score at that time was 12 .

After $36 \mathrm{~h}$ of ICU stay resistant septic shock with highdose catecholamine support, left ventricular dysfunction with $\mathrm{EF}$ of $20 \%$ persited and renal failure (serum creatinine $379 \mu \mathrm{mol} / \mathrm{l}$, daily urine output $<500 \mathrm{ml}$ ) worsened. SatcrO2 was $78 \%$, body temperature $37{ }^{\circ} \mathrm{C}$ and SOFA score increased to 13 .

In addition to echocardiography, Pulse Contour Cardiac Output (PiCCO) catheter was inserted to improve hemodynamic monitoring and demonstrated cardiac index $(\mathrm{CI})$ of $3.3 \mathrm{l} / \mathrm{min} / \mathrm{m}^{2}$ ) with stroke volume (SV) of $50 \mathrm{ml}$, increased global end-diastolic index (GEDI) to $1023 \mathrm{ml} / \mathrm{m}^{2}$ and extra vascular lung water index (ELWI) to $13.3 \mathrm{ml} / \mathrm{kg}$ and decreased systemic vascular resistance index (SVRI) of 1672 dyn.s.cm ${ }^{-5} \cdot \mathrm{m}^{2}$.

Persistant hemodynamic instability and worsening renal failure led to the decision to start continuous veno-venous hemofiltration $(\mathrm{CVVH})$ combined with hemoadsoption treatment by CytoSorb ${ }^{\circ}$ membrane for the next $24 \mathrm{~h}$. The goal was to improve hemodynamic situation and modulate the inflammatory response in our splenectomised 


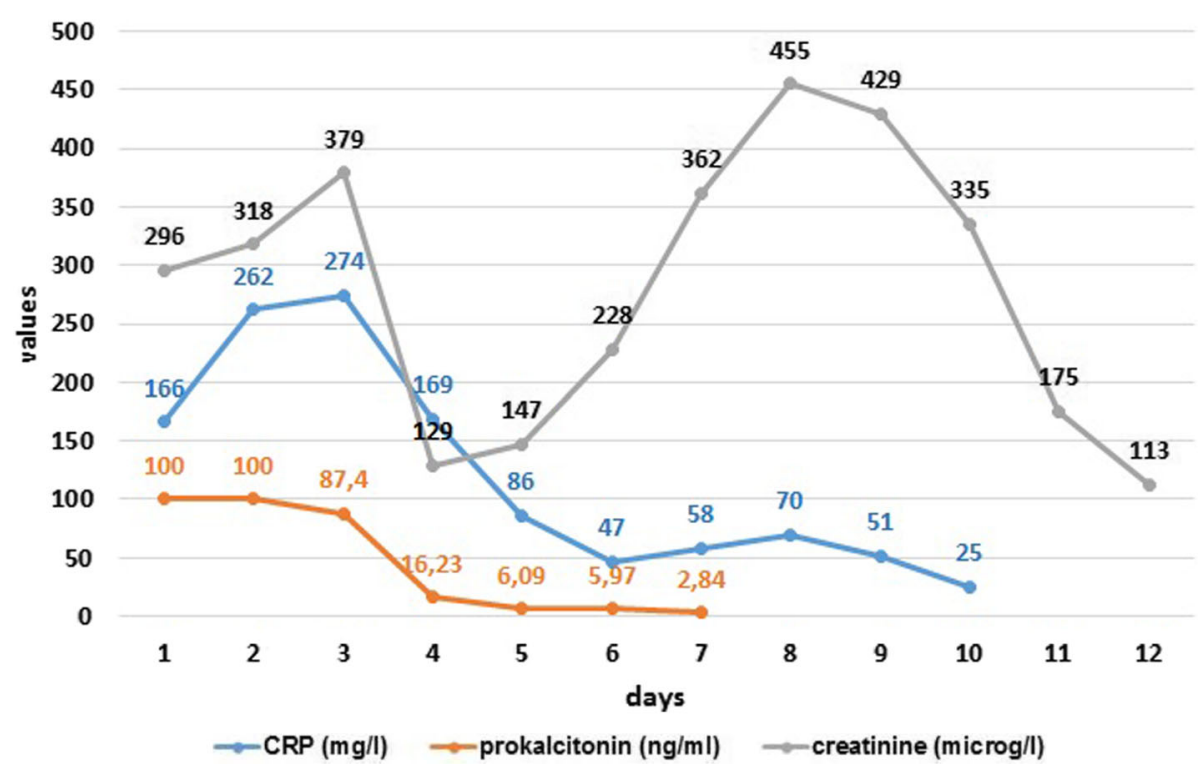

Fig. 1 Changes in CRP, procalcitonin and serum creatinine.

septic patient. Before the start of blood purification therapy, we measured serum IL-6 level, which was $114 \mathrm{pg} / \mathrm{ml}$.

After only $24 \mathrm{~h}$ of $\mathrm{CVVH}$ with concomitant use of a single CytoSorb ${ }^{\oplus}$ membrane EF increased to $45 \%$. PiCCO measurements improved as follows: GEDI changed to $805 \mathrm{ml} / \mathrm{m}^{2}$, ELWI to $11.2 \mathrm{ml} / \mathrm{kg}$, SVR to 1888 dyn.s.cm ${ }^{-5} . \mathrm{m}^{2}$ and CI to $3.95 \mathrm{~min} / \mathrm{m}^{2}$ and SV to $61 \mathrm{ml}$. The patient's temperature was $37{ }^{\circ} \mathrm{C}$ and SOFA score 11. IL-6 dropped from $114 \mathrm{pg} / \mathrm{ml}$ to $14,2 \mathrm{pg} / \mathrm{ml}$ after termination of hemoadsoption therapy.

We could stop the use of dobutamine, norepinephrine and vasopressin. The next day SOFA score was seven. Serum lactate and arterial $\mathrm{pH}$ turned to normal within few days, as well as CRP, procalcitonin (Fig. 1), leucocyte and platelet count after 14 days (Fig. 2). Table 1 presents the course of the treatment.

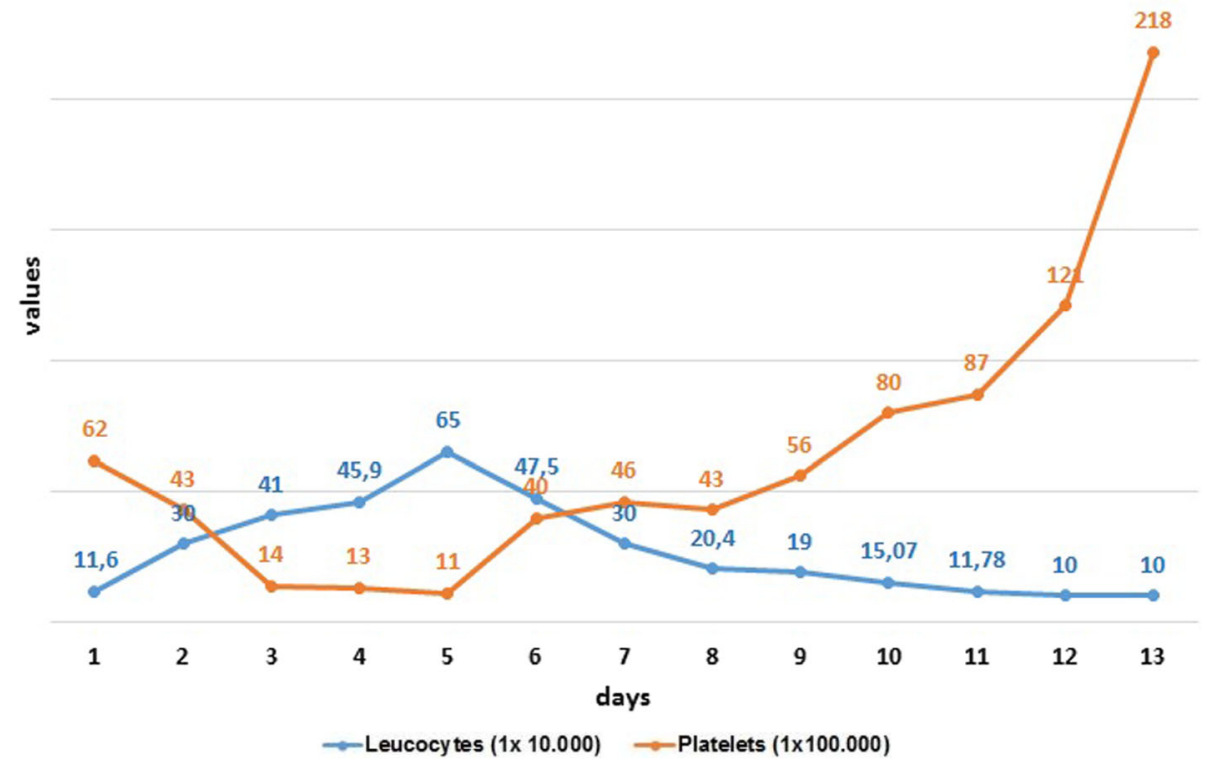

Fig. 2 Changes in leucocytes and platelets. 
Table 1 Time line table

\begin{tabular}{|c|c|}
\hline Date & Relevant past medical history and interventions \\
\hline 2011 & coat cell lymphoma diagnosed and chemotherapy perfo \\
\hline 2013 & splenectomy performed \\
\hline 2014 & autologous bone marrow transplantation performed \\
\hline Dates & Summaries from initial and follow-up visits \\
\hline 10.10. 2015 & $\begin{array}{l}\text {-Initial visit (admission to ICU): After } 24-\mathrm{h} \text { of fever and } \\
\text { malaise the patient was admitted somnolent, breathing } \\
\text { spontaneously with cold, wet and pale skin, } 38^{\circ} \mathrm{C} \text { of } \\
\text { fever; blood pressure } 50 / 40 \mathrm{mmHg} \text {, puls } 120 / \text { min, } \\
\text { eupnoeic, with rales over both lungs, without heart } \\
\text { murmurs, soft and painless abdomen with audible } \\
\text { peristalsis. } \\
\text {-After } 30-45 \text { min of therapy: } \\
\text { Oriented, breathing spontaneously, blood pressure } \\
\text { was } 110 / 65 \mathrm{mmHg} \text {, puls } 120 / \mathrm{min} \\
\text {-After } 2 \mathrm{~h} \text { of therapy: } \\
\text { Oriented, breathing spontaneously, blood pressure } \\
\text { was } 100 / 60 \mathrm{mmHg} \text { to } 120 / 80 \mathrm{mmHg} \text {, puls } 120 / \mathrm{min} \text {, } \\
\text { diuresis } 20 / \mathrm{min} \text {, SOFA score } 8\end{array}$ \\
\hline
\end{tabular}

11.10.2015 Oriented, breathing spontaneously, blood pressure was $110 / 60 \mathrm{mmHg}$ to $120 / 60 \mathrm{mmHg}$, puls $140-100 / \mathrm{min}$, diuresis $225 \mathrm{ml} / 24 \mathrm{~h}$, SOFA score 12

12.10.2015 Oriented, breathing spontaneously, blood pressure was $100 / 60 \mathrm{mmHg}$ to $120 / 80 \mathrm{mmHg}$, puls $130-100 / \mathrm{min}$, diuresis $225 \mathrm{ml} / 24 \mathrm{~h}$, SOFA score 13

13.10.2015 Oriented, breathing spontaneously, afebrile, blood pressure was $120 / 60 \mathrm{mmHg}$ to $120 / 80 \mathrm{mmHg}$, puls 130-100/min, diuresis $200 \mathrm{ml} / 24$ h, SOFA score 11

14.10.2015 Oriented, breathing spontaneously, afebrile, blood pressure was 120/100 mmHg, puls 120-100/min, diuresis $200 \mathrm{ml} / 24 \mathrm{~h}$, SOFA score 7

15.10.2015 Oriented, breathing spontaneously, afebrile, blood pressure was $140 / 100 \mathrm{mmHg}$, puls $110 / \mathrm{min}$, diuresis $690 \mathrm{ml} / 24 \mathrm{~h}$
Diagnostic testing, including dates

\section{-pulse oximetry}

-standard ECG

-continuous ECG monitoring

-insertion of central venous, arterial and urine catheters to measure arterial blood pressure continuously, central venous pressure

intermittently and urine output

per hour

-ultrasound of vena cava inferior

and $\mathrm{EF}$

-laboratory tests

-Chest roentgenogram

-microbiological cultures

-pulse oximetry

-continuous ECG, arterial blood

pressure, intermittent central venous pressure monitoring and hourly urine output

-ultrasound of vena cava inferior

and $\mathrm{EF}$

-laboratory tests

-Chest roentgenogram

-PiCCO catheter insertion and

hemodynamic measurements

-pulse oximetry

-continuous ECG, arterial blood pressure, intermittent central venous pressure monitoring and hourly urine output

-ultrasound of vena cava inferior and $E F$

-laboratory tests

-Hemodynamic measurements

by PiCCO catheter

-pulse oximetry

-continuous ECG, arterial blood

pressure, intermittent central venous pressure monitoring and hourly urine output

-ultrasound of vena cava inferior and $\mathrm{EF}$

-laboratory tests

- Hemodynamic measurements

by PiCCO catheter

-pulse oximetry

-continuous ECG, arterial blood

pressure, intermittent central venous pressure monitoring and hourly

urine output

-ultrasound of vena cava inferior

and $\mathrm{EF}$

-laboratory tests

-Hemodynamic measurements

by PiCCO catheter

Chest radiogram

-pulse oximetry

-continuous ECG, arterial blood

pressure, intermittent central venous
Interventions

$-2 L$ of oxygen by nasal cannula. -rapid infusion of crystalloids, -noradrenalin iv. infusion -dobutamine iv. -glucocorticoids iv. -vasopressin

- Imipenem iv.

$-40 \%$ of oxygen by mask -infusion of crystalloids, noradrenalin, dobutamine, vasopressin -glucocorticoids iv. -imipenem iv.

$-40 \%$ of oxygen by mask -infusion of crystalloids, noradrenalin, dobutamine, vasopressin -glucocorticoids iv. -imipenem iv. -CWH and CytoSorb ${ }^{\oplus}$ started

$40 \%$ of oxygen by mask -infusion of crystalloids, noradrenalin, -glucocorticoids iv. -imipenem iv. -CWH and Cyrosorb terminated

$40 \%$ of oxygen by mask -infusion of crystalloids, -imipenem iv.

$40 \%$ of oxygen by mask -infusion of crystalloids, -imipenem iv. 
Table 1 Time line table (Continued)

\begin{tabular}{|c|c|c|c|}
\hline Date & Relevant past medical history and interventions & & \\
\hline & & $\begin{array}{l}\text { pressure monitoring and hourly } \\
\text { urine output } \\
\text {-ultrasound of vena cava inferior } \\
\text { and EF } \\
\text {-laboratory tests } \\
\text {-Hemodynamic measurements by } \\
\text { PiCCO catheter }\end{array}$ & $-\mathrm{CWH}$ \\
\hline 16.10 .2015 & $\begin{array}{l}\text { Oriented, breathing spontaneously, sub febrile, } \\
\text { blood pressure was 150/90 mmHg, puls 100-120/min, } \\
\text { diuresis } 4455 \mathrm{ml} / 24 \mathrm{~h}\end{array}$ & $\begin{array}{l}\text {-pulse oximetry } \\
\text {-continuous ECG, arterial blood } \\
\text { pressure, hourly urine output } \\
\text {-laboratory tests } \\
\text {-Hemodynamic measurements } \\
\text { by PiCCO catheter }\end{array}$ & $\begin{array}{l}-35 \% \text { of oxygen by mask } \\
\text {-infusion of crystalloids, } \\
\text {-imipenem iv. } \\
\text {-CWH intermittently }\end{array}$ \\
\hline 17.10 .2015 & $\begin{array}{l}\text { Oriented, breathing spontaneously, afebrile, } \\
\text { blood pressure was 140/70 mmHg, puls } 95-110 / \mathrm{min} \text {, } \\
\text { diuresis } 6870 \mathrm{ml} / 24 \mathrm{~h}\end{array}$ & $\begin{array}{l}\text {-pulse oximetry } \\
\text {-continuous ECG, arterial blood } \\
\text { pressure, hourly urine output } \\
\text {-ultrasound of vena cava inferior } \\
\text {-laboratory tests }\end{array}$ & $\begin{array}{l}31 \% \text { of oxygen by mask } \\
\text {-infusion of crystalloids, } \\
\text {-imipenem iv. } \\
\text {-CWH intermittently }\end{array}$ \\
\hline 18.10 .2015 & $\begin{array}{l}\text { Oriented, breathing spontaneously, afebrile, } \\
\text { blood pressure was } 150 / 80 \mathrm{mmHg} \\
\text { puls } 90-110 / \mathrm{min} \text {, diuresis } 4540 \mathrm{ml} / 24 \mathrm{~h}\end{array}$ & $\begin{array}{l}\text {-pulse oximetry } \\
\text {-continuous ECG, arterial blood } \\
\text { pressure, urine output per day } \\
\text {-laboratory tests }\end{array}$ & $\begin{array}{l}3 \text { I of oxygen by nasal cannula } \\
\text {-infusion of crystalloids, } \\
\text {-imipenem iv. } \\
\text {-CWH intermittently }\end{array}$ \\
\hline 19.10. 2015 & $\begin{array}{l}\text { Oriented, breathing spontaneously, afebrile, } \\
\text { blood pressure was } 160 / 80 \mathrm{mmHg} \\
\text { puls } 70-80 / \mathrm{min} \text {, diuresis } 4000 \mathrm{ml} / 24 \mathrm{~h}\end{array}$ & $\begin{array}{l}\text {-pulse oximetry } \\
\text {-continuous ECG, arterial blood } \\
\text { pressure, urine output per day } \\
\text {-laboratory tests }\end{array}$ & $\begin{array}{l}\text { 1 I of oxygen by nasal cannula } \\
\text {-infusion of crystalloids, } \\
\text {-imipenem iv. } \\
\text {-CWH intermittently } \\
\text {-transferred to nephrology ward }\end{array}$ \\
\hline
\end{tabular}

Legend: ICU intensive care unit, ECG electrocardiogram, EF ejection fraction, PiCCO Pulse Contour Cardiac Output, CVVH continuous veno-venous hemofiltration

For regeneration of the kidney function the patient received CVVH intermittently for another 21 days. She was discharged from ICU after 10 days and from the hospital after 76 days.

\section{Discussion and conclusions}

The case describes our clinical experience with the use of hemoadsoption membrane CytoSorb ${ }^{\circ}$ in combination with $\mathrm{CVVH}$ in a patient with Streptococcal pneumonia, complicated by sepsis and septic shock. We used hemoadsoption as an adjunctive therapy and in combination with $\mathrm{CVVH}$ in order to control the release of cytokines in a hemodynamically unstable patient.

In one systematic review of human studies on techniques of extracorporeal cytokine removal, standard or ultrafiltration techniques appeared to be inefficient or unreliable in removing cytokines even when coupled with high volume hemofiltration. In the same systematic review adsorption techniques showed promising results based on percentage of cytokins removed, although the data were limited [11]. A small study on 13 critically ill patients with severe sepsis and septic shock, showed an increased transcriptional activity of IL-6 during CVVH, suggesting an immunomodulatory effect during CVVH [12].

Blood purification techniques optimise circulating blood volume and plasma colloid osmotic pressure, correct electrolyte disorders, azotaemia and concomitant metabolic acidosis, decrease body temperature and therefore improve hemodynamic situation. Some decreases in lactate levels, in temperature and in inflammatory marker can be observed as well [11].

In our case we observed significant improvement after CVVH combined with hemoadsorption in echocardiographic measurements of EF (an increase from 20 to 45\%) and PiCCO catheter measurements (CI increased from $3.3 \mathrm{~L} / \mathrm{min} / \mathrm{m}^{2}$ to $3,95 \mathrm{~L} / \mathrm{min} / \mathrm{m}^{2}$ and $\mathrm{SV}$ from $50 \mathrm{ml}$ to $61 \mathrm{ml}$ ). In addition, there was a decrease in the need of vasoactive agents to maintain normotension and adequate cardiac function. We also observed that IL-6 level dropped (from $114 \mathrm{pg} / \mathrm{ml}$ to $14,2 \mathrm{pg} / \mathrm{ml}$ ).

We observed that CI measurements in our patient underestimated the cardiac function, what is not surprising as it depends on both - heart rate and stroke volume. EF measurements by echocardiography more adequately reflected cardiac systolic function, what was already demonstrated by other authors [2].

Clinical studies stress the importance of early treatment by hemoadsoption membranes such as CytoSorb ${ }^{\circ}$, in particular within 24-48 h after admission in order to diminish the cytokine storm, responsible for hemodynamic instability in septic shock patients [9]. One of the reasons to start $\mathrm{CytoSorb}^{\oplus}$ therapy $36 \mathrm{~h}$ from admission was the 
worsening difficult-to-manage gram-positive septic shock in our splenectomised patient, where the risk of mortality is significantly increased [13].

The reason to continue carbapenem therapy was the fulminant course of infection with septic shock in splenectomised patient. In addition, we only obtained positive pneumococcal urine antigen, but no other specific microbiological cultures to confirm pneumococcal infection.

Transient and significant systolic myocardial dysfunction of the left ventricle (EF 20\%) in our septic patient suggested the presence of septic cardiomyopathy as the consequence of increased production of cytokines in a fulminant grampositive infection $[1,2,4]$.

In our patient, we used low dose dobutamine, instead of levosimendan. "Surviving Sepsis Campaign" in 2016 recommends dobutamine as the first line inotropic agent. However, levosimendan increases cardiac myocyte calcium responsiveness and opens ATP-dependent potassium channels, that could exert a more beneficial effect in sepsis-induced myocardial depression [14]. However, due to its higher risk of supraventricular tachyarrhythmia in our patient who was already in sinus tachycardia with the heart rate of $120-130 / \mathrm{min}$, we did not use it. In addition, its long half-life of several weeks limits the practicality of its use in acute shock states [15].

The normal ECG, the absence of chest pain and normal troponin I levels excluded myocardial ischemia as the cause of systolic dysfunction. In our patient, the beneficial effect of CVVH, combined with hemoadsorption, also confirmed a rapid drop in serum lactate, reflecting the reversal of anaerobic metabolism, specific for severe septic shock. This finding is consistent with other studies $[16,17]$.

Our case suggests that early removal of inflammatory cytokines enables a significant reversal of circulatory failure and in addition, a significant improvement of left ventricular systolic function of septic cardiomyopathy, resulting in improved hemodynamic status, lactacidosis and clinical outcome in septic patients.

\section{Abbreviations}

Cl: Cardiac index; CRP: C-reactive protein; CWHD: Continuous veno-venous hemofiltration; ECG: Electrocardiogram; EF: Ejection fraction; ELWI: Extra vascular lung water index; GEDI: Global end-diastolic index; ICU: Intensive care unit; IL: Interleukins; NT-proBNP: N-terminal-pro brain natriuretic peptide; PiCCO: Pulse Contour Cardiac Output; SatO2: Oxygen saturation;

SVRI: Systemic vascular resistance index; TNF-a: Tumor necrosis factor-a

Availability of data and materials

The datasets used and/or analysed during the current study are available from the corresponding author on reasonable request.

\section{Authors' contributions}

$\mathrm{SA}, \mathrm{KB}, \mathrm{MA}$ equally participated in patient treatment, decision of treatment modalities, SA wrote the manuscript. All authors read and approved the final manuscript.

\section{Consent for publication}

Written informed consent was obtained from the patient for publication of this case report.

\section{Competing interests}

The authors declare that they have no competing interests.

\section{Publisher's Note}

Springer Nature remains neutral with regard to jurisdictional claims in published maps and institutional affiliations.

Received: 25 December 2017 Accepted: 13 August 2018

Published online: 29 August 2018

\section{References}

1. Mueller-Werdan U, Buerke M, Ebelt H, Heinroth KM, Herklotz A, Loppnowet $\mathrm{H}$, et al. Septic cardiomyopathy - a not yet discovered cardiomyopathy? Exp Clin Cardiol. 2006;11:226-36.

2. Vieillard-Baron A. Septic cardiomyopathy. Ann Intensive Care. 2011;1:6. https://doi.org/10.1186/2110-5820-1-6.

3. Sato R, Nasu M. A review of sepsis-induced cardiomyopathy. J Intensive Care. 2015;3:48. https://doi.org/10.1186/s40560-015-0112-5.

4. Cimolai MC, Alvarez S, Bode C, Bugger H. Mitochondrial mechanisms in septic cardiomyopathy. Int J Mol Sci. 2015;16:17763-78. https://doi.org/10. 3390/ijms160817763.

5. Hobai IA, Edgecomb J, LaBarge K, Colucci WC. Dysregulation of intracellular calcium transporters in animal models of sepsis induced cardiomyopathy. Shock. 2015;43:3. https://doi.org/10.1097/SHK.0000000000000261.

6. Krüttgen A, Rose-John A. Interleukin-6 in Sepsis and capillary leakage syndrome. J Interf Cytokine Res. 2012;32:60-5.

7. Peng Z-Y, Carter MJ, Kellum JA. Effects of hemoadsorption on cytokine removal and short-term survival in septic rats. Crit Care Med. 2008;36:1573-7.

8. Venkataraman R, Subramanian S, Kellum JA. Clinical review: extracorporeal blood purification in severe sepsis. Crit Care. 2003;7:139. https://doi.org/10. 1186/cc1889.

9. Kogelmann K, Jarczak D, Scheller M, Drüner M. Hemoadsorption by CytoSorb in septic patients: a case series. Crit Care. 2017;21:74. https://doi. org/10.1186/s13054-017-1662-9.

10. Esteban E, Ferrer R, Alsina L, Artigas A. Immunomodulation in Sepsis: the role of endotoxin removal by Polymyxin B-immobilized cartridge. Mediat Inflamm. 2013; https://doi.org/10.1155/2013/507539

11. Atan R, Crosbie DCA, Bellomo R. Techniques of extracorporeal cytokine removal: a systematic review of human studies. Ren Fail. 2013;35:1061-70.

12. Servillo G, Vargas M, Pastore A, et al. Immunomodulatory effect of continuous Venovenous hemofiltration during Sepsis: preliminary data. Biomed Res Int. 2013; https://doi.org/10.1155/2013/108951.

13. Leone G, Pizzigallo E. Bacterial infections following splenectomy for malignant and nonmalignant hematologic diseases. Mediterr J Hematol Infect Dis. 2015; https://doi.org/10.4084/MJHID.2015.05.

14. Rhodes A, Evans LE, Alhazzani W, Levy MM, Antonelli M, Ferrer R, et al. Surviving Sepsis Campaign: International Guidelines for Management of Sepsis and Septic Shock: 2016. Intensive Care Med. 2017:43:304-77. https:// doi.org/10.1007/s00134-017-4683-6.

15. Morelli A, De Castro S, Teboul JL, Singer M, Rocco M, Conti G, et al. Effects of levosimendan on systemic and regional hemodynamics in septic myocardial depression. Intensive Care Med. 2005;31:638-44.

16. Burkovskiy I, Sardinha J, Zhou J, Lehmann C. Cytokine release in sepsis. Adv Biosci Biotechnol. 2013; https://doi.org/10.4236/abb.2013.49114

17. Chaudry H, Zhou J, Zhong Y, Ali MM, McGuire F, Nagarkatti PS, et al. Role of cytokines as a double-edged sword in Sepsis. In Vivo. 2013;27:669-84. 